\title{
HETEROTOPIC INTRATHORACIC LIVER
}

\author{
BY \\ B. T. LE ROUX \\ From the Departments of Surgery, University of Edinburgh
}

(RECEIVED FOR PUBLICATION MAY 30, 1960)

Accessory hepatic tissue, unlike accessory splenic and pancreatic tissue, is rare, and has a limited and almost exclusively subdiaphragmatic distribution (Willis, 1958). Only one example of supradiaphragmatic heterotopic liver has been found in the literature (Hansbrough and Lipin, 1957). A second example of this unusual anomaly is described, and is similar in nearly every detail to the case mentioned above. This very similarity suggests that the developmental aberration which results in hepatic tissue lodging above the diaphragm is reproducible, and that other cases are likely to be found. The lesion is symptomless and harmless, and if further examples are found that follow a pattern similar to the two known cases, awareness of the occurrence of the lesion may ultimately obviate the need for diagnostic thoracotomy.

\section{CASE History}

A healthy 18-year-old symptomless boy was radiographed as part of a routine survey when a triangular opacity was seen to occupy the right costophrenic angle. By the induction of a pneumoperitoneum the opacity was demonstrated to lie on the cephalad side of the diaphragm (Fig. 1). The right subphrenic space was well filled with air and the diaphragmatic surface of the liver was smooth and featureless. Air did not enter the pleural space. By the induction of a pneumothorax the opacity was shown to be free from lung and lateral chest wall. No other information was obtained from pre-operative investigations. There were no clinical abnormalities.

Right lateral thoracotomy was undertaken in February, 1954. A purple tumour, described as being slightly smaller than and looking like an adult spleen, lay on the diaphragm and was attached to this by a strap-like pedicle, $3 \mathrm{~cm}$. long and $1 \mathrm{~cm}$. broad. Pleura was reflected from the cephalad surface of the diaphragm on to the pedicle and enveloped the mass. Dissection of the pedicle showed that it contained an artery, two veins, and a duct containing bile. The vessels in the pedicle passed through a defect in the diaphragm into the right coronary ligment and thence into the liver. The defect in the diaphragm was pearshaped, its margins were muscular, and it was about $1.5 \mathrm{~cm}$. in its longest diameter. The pedicle was ligated, the lump amputated, and the defect in the diaphragm closed with interrupted silk sutures. Convalescence was uneventful and the patient remains well six years later.

The resected specimen was covered with a smooth capsule. On section it had the appearances of liver, with the vessels in the pedicle entering a hilum. Lobulation was seen on the cut surface (Fig. 2). The histological appearances were those of normal liver, with smaller bile ducts perhaps more numerous than usual. The specimen was examined by the panel of pathologists of the Registry of Benign Tumours at the Brompton Hospital, London.

\section{Pathogenesis}

The occurrence of hepatic tissue above the diaphragm can be related to an anomaly of development of both liver and diaphragm, the developments of which are closely related. The hepatic bud grows from the foregut into the septum transversum and divides into a larger

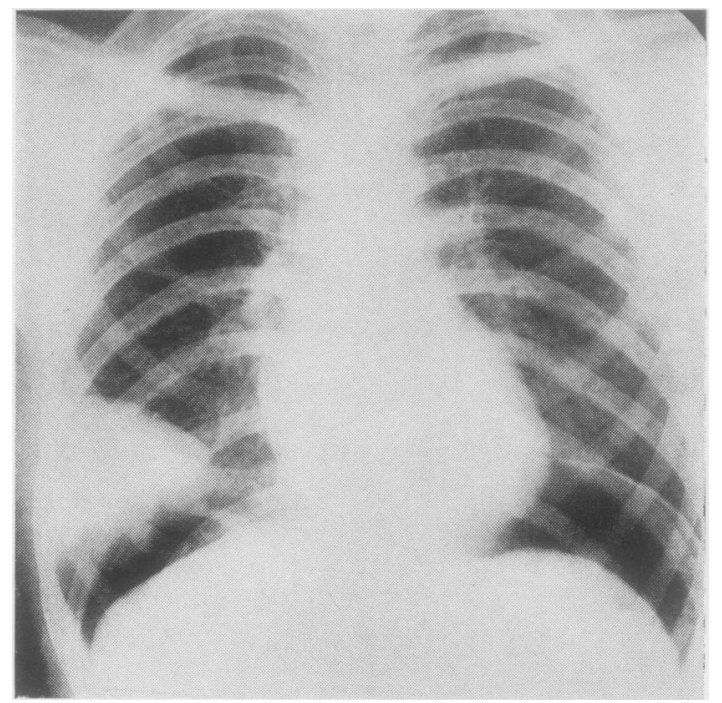

FIG. 1.-Postero-anterior view after the induction of a pneumo peritoneum, showing the triangular opacity occupying the right costophrenic angle. 


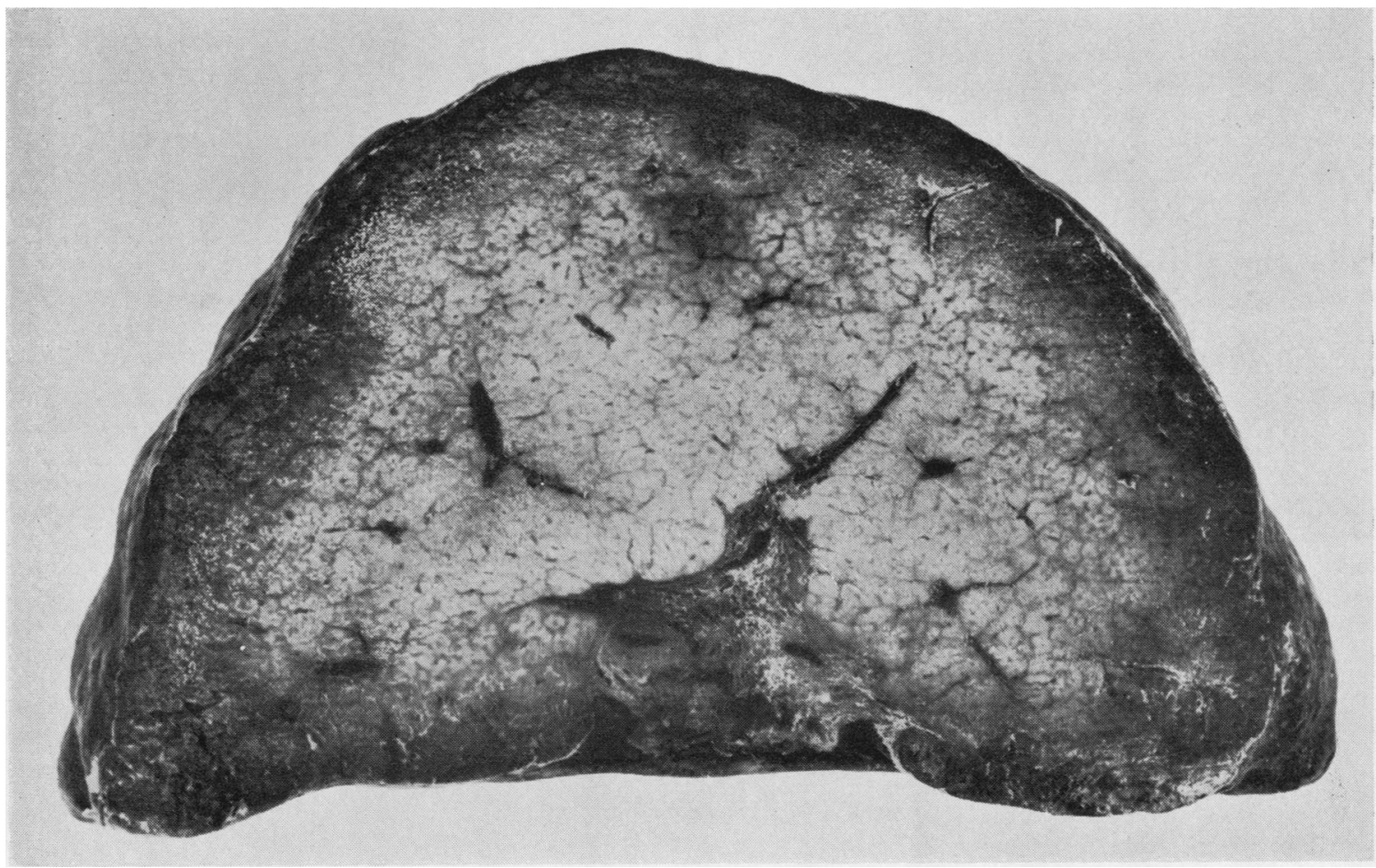

Fig. 2.-The cut surface of the resected specimen; the vessels at the hilum and the lobulation can be seen.

cranial and a smaller caudal portion. The former, the pars hepatica, proliferates in the mesenchymal tissues of the septum transversum. Proliferation is disproportionately rapid in comparison with the rest of the embryo, and in the $35 \mathrm{~mm}$. embryo the liver constitutes $10 \%$ of body weight (Hamilton, Boyd, and Mossman, 1945). The central tendon of the diaphragm develops from the septum transversum. The paired pleuro-peritoneal membranes, and the oesophageal mesentery between them, form the dorsal portion of the diaphragm, and circumferentially the pleuroperitoneal membranes are augmented by continued expansion of the lungs and pleural cavities into the body wall. Between the central and peripheral portions of the developing diaphragm rapidly proliferating hepatic tissue has the opportunity of extending into the developing pleural space through the pleuro-peritoneal canal. The pleuroperitoneal canal on the right diminishes in size with growth of the liver, the lung, and the coelomic spaces, and by myoblastic invasion of the peripheral parts of the developing diaphragm. The opportunity therefore exists for the supraphrenic sequestration of hepatic tissue with diminution in size of the pleuro-peritoneal canal, and it would be expected that this sequestered hepatic tissue would retain continuity with the parent organ through its ducts and vessels. The defect in the diaphragm associated with both the reported cases of supradiaphragmatic heterotopic liver is believed to represent persistence of the pleuro-peritoneal canal on the right.

\section{SUMMARY}

An example of supradiaphragmatic heterotopic liver is described ; this is the second reported case. An explanation is offered for the occurrence of normal liver above the diaphragm.

\section{REFERENCES}

Hamilton, W. J., Boyd, J. D., and Mossman, H. W. (1945). Human Embryology. Heffer, Cambridge.

Hansbrough, E. T. and Lipin, R. J. (1957). Ann. Surg., 145, 564. Willis, R. A. (1958). The Borderland of Embryology and Pathology. Butterworths, London. 